\title{
Comparison of intravenous dexmedetomidine and lignocaine infiltration to attenuate the hemodynamic response to skull pin holder during craniotomy
}

\author{
Catherine Kapoor ${ }^{1}$, D Aruna², D Ashok Kumar ${ }^{3 *}$, Sanjana $S^{4}$
}

${ }^{1}$ Senior Assistant Professor, ${ }^{2}$ Senior Resident, 4 Junior Resident, Department of Anesthesiology, RGGGH Madras Medical College, Chennai, Tamil Nadu, INDIA.

${ }^{3}$ Associate Professor, Department of Anesthesiology, Government Medical College, Chennai, Tamil Nadu, INDIA.

Email: ashokpainclinic@gmail.com

\begin{abstract}
Background: The purpose of the study is to compare the effectiveness of intravenous dexmedetomidine or lignocaine infiltration in attenuating the hemodynamic response to skull pin holder during craniotomy. For the study, 60 patients of the age group 18-70 years belonging to ASA PS I and PS II were selected and divided into two groups. The study design employed was a prospective randomized comparative study. Based on standard dosing, $1 \mathrm{mcg} / \mathrm{kg}$ of dexmedetomidine diluted to $10 \mathrm{ml}$ with $0.9 \%$ saline over 10 minutes was given before induction. Patients randomized to group lignocaine received infiltration of pin sites with $2 \%$ lignocaine $3 \mathrm{ml}$ at each site. The timing of dexmedetomidine infusion was such that peak effect of the drug would coincide with the time of application. Heart rate and mean arterial pressure were comparable between the two groups during the study and were recorded at the following intervals pre-induction, preinfiltration, post-infiltration, pre pin application, post pin application 10 and 15 minutes after pin application. We found that dexmedetomidine is more effective in controlling the hemodynamic response than local lignocaine infiltration during craniotomy. It was concluded that $1 \mathrm{mcg} / \mathrm{kg}$ of dexmedetomidine infused slowly over 10 minutes is superior when compared to local infiltration of $2 \%$ lignocaine in attenuating the hemodynamic response to skull pin holder during craniotomy. By attenuating the hemodynamic response, brain edema, increased intracranial pressure and intracranial hemorrhage can be prevented.

Keywords- Hemodynamic, Lidocaine, Dexmedetomidine, Craniotomy,skull pin holder
\end{abstract}

*Address for Correspondence:

Dr D Ashok Kumar, Senior Associate Professor, Department of Anesthesiology, Government Medical College, Chennai, Tamil Nadu, INDIA. Email: ashokpainclinic@gmail.com

Received Date: 02/06/2020 Revised Date: 13/07/2020 Accepted Date: 25/08/2020

DOI: https://doi.org/10.26611/10151611

This work is licensed under a Creative Commons Attribution-NonCommercial 4.0 International License. (cc)) EY-NC

\begin{tabular}{|l|l|}
\hline \multicolumn{2}{|c|}{ Access this article online } \\
\hline Quick Response Code: & Website: \\
\hline & www.medpulse.in \\
& \\
\hline
\end{tabular}

\section{INTRODUCTION}

Application of skull pin holder during craniotomy for neurosurgical procedure is extremely painful and is associated with abrupt increase in heart rate and mean arterial pressure. These adverse effects can lead to brain edema, increased intracranial pressure or hemorrhage. The Mayfield skull pin holder is used to support the head without any direct pressure on the face allowing access to the airway and can holds the head for optimal neurosurgical exposure. Different techniques have been used to blunt these deleterious hemodynamic changes. The hemodynamic response consists of autonomic response to noxious stimuli which increases the sympathetic tone which elevates the blood pressure and heart rate. The 
sudomotor responses consists of sweating whereas the hormonal response consists of release of corticosteroids, glucagon, and catecholamines due to activation of hypothalamic pituitary axis due to surgical stress. Dexmedetomidine, an alpha 2 agonist may blunt the hemodynamic response due to its sympatholytic and analgesic properties. Lignocaine being a local anaesthetic blocks the nerve conduction by decreasing the entry of sodium ions during upstroke of action potential thus decreasing the autonomic response.

\section{MATERIALS AND METHODS PATIENT SELECTION}

Sixty consecutive ASA PS I and PS II aged between 18 to 70 years undergoing elective craniotomy for resection of supratentorial tumors with aid of skull pin holder were selected and randomized into two groups. Group 1 received intravenous dexmedetomidine and group 2 received local lignocaine infiltration.

\section{EXCLUSION CRITERIA}

1. Hypertension

2. Ischemic heart disease

3. Heart block

4. Pregnancy or lactation

5. Signs and symptoms of raised intracranial pressure

6. Previous craniotomy

7. Tumors of hypophysis

8. Head injury

9. Patient not willing to participate

\section{MATERIALS}

- $18 \mathrm{G}$ venflon

- Drugs -dexmedetomidine, $2 \%$ lignocaine

- Drugs for general anaesthesia-glycopyrrolate, propofol, atracurium, fentanyl

- Monitors-ECG,NIBP,Spo2,EtCO2

- This study was done in department of anaesthesia, RGGGH, Chennai

STATISTICAL ANALYSIS

Results for parametric data were reported as means+-SD. Demographic data were analyzed by student t-tests. Hemodynamic data were analyzed by independent t-test for differences between group and paired t-test for differences within groups. For post - hoc comparison, Bonferroni test. A value of $<0.05$ was considered statistically significant

\section{METHODOLOGY}

After ethical committee approval, patients satisfying inclusion criteria after obtaining consent were randomized by closed envelope method. Group 1 received intravenous dexmedetomidine $1 \mathrm{mcg} / \mathrm{kg}$ diluted to $10 \mathrm{mg}$ of saline over 10 minutes before induction. These patients received infiltration of $0.9 \%$ saline at the pin site to ensure blinding of observer. Patients randomized to group 2 received $10 \mathrm{ml}$ of $0.9 \%$ saline intravenously before induction and then received infiltration of pin sites with $2 \%$ lignocaine $3 \mathrm{mg}$ at each site. The heart rate and the mean arterial pressure were recorded at following time intervals

- Pre induction T1 (before intravenous dexmedetomidine)

- Pre infiltration T2 (before infiltration of 2\%lignocaine)

- Post infiltration T3

- Pre pin application T4

- Post pin application T5

- 10 minutes after pin application T 10

- 15 minutes after pin application T 15

Surgery was proceeded with maintenance of general anaesthesia and after extubation, data compilation and statistical analysis was done

\section{OBSERVATION AND ANALYSIS}

Results for parametric data were reported as means + - SD. Demographic data were analyzed by Student t-tests. Hemodynamic data were analyzed by independent t-test for differences between group and paired t-test for differences within groups. For post - hoc comparison, Bonferroni test. A value of $<0.05$ was considered statistically significant While analyzing the age distribution, gender, ASA PS, among the intervention groups using unpaired t-test, the data was found to be statistically insignificant $(\mathrm{p}>0.05)$

\section{RESULTS}

\begin{tabular}{|c|c|c|c|c|c|}
\hline HR & GROUP & $\mathbf{N}$ & MEAN & $\begin{array}{c}\text { STD. } \\
\text { DEVIATION }\end{array}$ & $\begin{array}{l}\text { P VALUE BY “ } \mathrm{t} \text { ” } \\
\text { TEST }\end{array}$ \\
\hline \multirow[t]{2}{*}{ Baseline (T1) } & DEXOMED & 30 & 80.97 & 5.25 & 0.924 \\
\hline & LIGNOCAINE & 30 & 81.10 & 5.50 & \\
\hline \multirow[t]{2}{*}{ Before administration of dexmed/local infiltration (T2) } & DEXOMED & 30 & 81.50 & 5.01 & 0.920 \\
\hline & LIGNOCAINE & 30 & 81.63 & 5.26 & \\
\hline \multirow[t]{2}{*}{ After administration of dexmed/ local infiltration (T3) } & DEXOMED & 30 & 72.00 & 4.58 & $<0.001$ \\
\hline & LIGNOCAINE & 30 & 77.00 & 5.19 & \\
\hline
\end{tabular}




\begin{tabular}{cccccc}
\hline Prepin application (T4) & DEXOMED & 30 & 71.87 & 4.11 & $<0.001$ \\
& LIGNOCAINE & 30 & 76.87 & 4.82 & \\
Postpin application (T5) & DEXOMED & 30 & 72.90 & 4.04 & $<0.001$ \\
& LIGNOCAINE & 30 & 77.87 & 4.71 & \\
10 min postpin application (T10) & DEXOMED & 30 & 72.37 & 3.55 & 0.001 \\
& LIGNOCAINE & 30 & 76.07 & 4.51 & \\
15 min postpin application (T15) & DEXOMED & 30 & 72.10 & 3.62 & $<0.001$ \\
& LIGNOCAINE & 30 & 76.40 & 3.94 & \\
\hline
\end{tabular}

While analyzing the heart rate distribution among patients undergoing craniotomy using skull pin holder using unpaired ttest, it was observed that attenuation of heart rate in dexmedetomidine group was better than lignocaine and results were found to be statistically significant $(\mathrm{p}<0.05)$.

\begin{tabular}{|c|c|c|c|c|c|}
\hline SBP & GROUP & $\mathbf{N}$ & MEAN & $\begin{array}{c}\text { STD. } \\
\text { DEVIATION }\end{array}$ & $\begin{array}{l}\text { P VALUE BY “t” } \\
\text { TEST }\end{array}$ \\
\hline \multirow[t]{2}{*}{ Baseline (T1) } & DEXOMED & 30 & 125.60 & 9.39 & 0.748 \\
\hline & LIGNOCAINE & 30 & 126.40 & 9.79 & \\
\hline \multirow[t]{2}{*}{ Before administration of dexmed/local infiltration (T2) } & DEXOMED & 30 & 125.40 & 8.36 & 0.823 \\
\hline & LIGNOCAINE & 30 & 125.90 & 8.90 & \\
\hline \multirow[t]{2}{*}{ After administration of dexmed/ local infiltration (T3) } & DEXOMED & 30 & 114.80 & 6.71 & 0.002 \\
\hline & LIGNOCAINE & 30 & 121.00 & 7.95 & \\
\hline \multirow[t]{2}{*}{ Prepin application (T4) } & DEXOMED & 30 & 115.70 & 6.92 & 0.084 \\
\hline & LIGNOCAINE & 30 & 119.03 & 7.73 & \\
\hline \multirow[t]{2}{*}{ Postpin application (T5) } & DEXOMED & 30 & 116.43 & 6.71 & 0.034 \\
\hline & LIGNOCAINE & 30 & 120.40 & 7.38 & \\
\hline \multirow[t]{2}{*}{10 min postpin application (T10) } & DEXOMED & 30 & 113.10 & 6.02 & 0.005 \\
\hline & LIGNOCAINE & 30 & 117.80 & 6.40 & \\
\hline \multirow[t]{2}{*}{15 min postpin application (T15) } & DEXOMED & 30 & 111.47 & 5.14 & $<0.001$ \\
\hline & LIGNOCAINE & 30 & 117.20 & 5.90 & \\
\hline
\end{tabular}

While analysing the systolic BP distribution among patients undergoing craniotomy using skull pin holder using unpaired $t$ test,it was observed that attenuation of systolic BP in dexmedetomidine group was better than lignocaine and results were found to be statistically significant $(\mathrm{p}<0.05)$

\begin{tabular}{|c|c|c|c|c|c|}
\hline DBP & GROUP & $\mathbf{N}$ & MEAN & $\begin{array}{c}\text { STD. } \\
\text { DEVIATION }\end{array}$ & $\begin{array}{c}\text { P VALUE BY “ } \mathrm{t} \text { ” } \\
\text { TEST }\end{array}$ \\
\hline \multirow[t]{2}{*}{ Baseline (T1) } & DEXOMED & 30 & 79.10 & 6.21 & 0.157 \\
\hline & LIGNOCAINE & 30 & 81.53 & 6.91 & \\
\hline \multirow[t]{2}{*}{ Before administration of dexmed/local infiltration (T2) } & DEXOMED & 30 & 79.70 & 4.65 & 0.288 \\
\hline & LIGNOCAINE & 30 & 81.17 & 5.87 & \\
\hline \multirow[t]{2}{*}{ After administration of dexmed/ local infiltration (T3) } & DEXOMED & 30 & 72.97 & 4.55 & 0.001 \\
\hline & LIGNOCAINE & 30 & 77.53 & 5.48 & \\
\hline \multirow[t]{2}{*}{ Prepin application (T4) } & DEXOMED & 30 & 72.80 & 4.48 & 0.012 \\
\hline & LIGNOCAINE & 30 & 76.23 & 5.71 & \\
\hline \multirow[t]{2}{*}{ Postpin application (T5) } & DEXOMED & 30 & 74.13 & 4.74 & 0.043 \\
\hline & LIGNOCAINE & 30 & 76.23 & 5.70 & \\
\hline \multirow[t]{2}{*}{10 min postpin application (T10) } & DEXOMED & 30 & 72.20 & 4.85 & 0.005 \\
\hline & LIGNOCAINE & 30 & 76.03 & 5.20 & \\
\hline \multirow[t]{2}{*}{15 min postpin application (T15) } & DEXOMED & 30 & 70.73 & 4.49 & $<0.001$ \\
\hline & LIGNOCAINE & 30 & 76.07 & 4.73 & \\
\hline
\end{tabular}

While analysing the diastolic BP distribution among patients undergoing craniotomy using skull pin holder using unpaired $t$ test,it was observed that attenuation of diastolic BP in dexmedetomidine group was better than lignocaine and results were found to be statistically significant $(\mathrm{p}<0.05)$ 
Table 4: Mean arterial pressure

\begin{tabular}{|c|c|c|c|c|c|}
\hline MAP & GROUP & $\mathbf{N}$ & MEAN & $\begin{array}{c}\text { STD. } \\
\text { DEVIATION }\end{array}$ & $\begin{array}{l}\text { P VALUE BY “ } \mathrm{t} \text { ” } \\
\text { TEST }\end{array}$ \\
\hline \multirow[t]{2}{*}{ Baseline (T1) } & DEXOMED & 30 & 94.60 & 6.56 & 0.309 \\
\hline & LIGNOCAINE & 30 & 96.49 & 7.64 & \\
\hline \multirow[t]{2}{*}{ Before administration of dexmed/local infiltration (T2) } & DEXOMED & 30 & 94.33 & 5.54 & 0.273 \\
\hline & LIGNOCAINE & 30 & 96.08 & 6.63 & \\
\hline \multirow[t]{2}{*}{ After administration of dexmed/ local infiltration (T3) } & DEXOMED & 30 & 86.20 & 4.79 & $<0.001$ \\
\hline & LIGNOCAINE & 30 & 92.02 & 6.08 & \\
\hline \multirow[t]{2}{*}{ Prepin application (T4) } & DEXOMED & 30 & 87.10 & 4.94 & 0.022 \\
\hline & LIGNOCAINE & 30 & 90.50 & 6.16 & \\
\hline \multirow[t]{2}{*}{ Postpin application (T5) } & DEXOMED & 30 & 88.23 & 4.96 & 0.017 \\
\hline & LIGNOCAINE & 30 & 91.64 & 5.79 & \\
\hline \multirow[t]{2}{*}{10 min postpin application (T10) } & DEXOMED & 30 & 85.73 & 4.89 & 0.002 \\
\hline & LIGNOCAINE & 30 & 89.96 & 5.29 & \\
\hline \multirow[t]{2}{*}{15 min postpin application (T15) } & DEXOMED & 30 & 84.31 & 4.11 & $<0.001$ \\
\hline & LIGNOCAINE & 30 & 89.78 & 4.70 & \\
\hline
\end{tabular}

While analysing the mean arterial pressure distribution among patients undergoing craniotomy using skull pin holder using unpaired $t$ test, it was observed that attenuation of mean arterial pressure in dexmedetomidine group was better than lignocaine and results were found to be statistically significant $(\mathrm{p}<0.05)$

\section{DISCUSSION}

Different modalities have been experimented with to reduce the hemodynamic response to skull pin application of which the most commonly studied modality has been local lignocaine infiltration at pin sites. However, this was not successful because of improper infiltration, change in pin sites, head movement during fixation and inadequate dosage of local anaesthetics. This resulted in comparison of local lignocaine infiltration with other modalities such as oral clonidine or gabapentin pre-medication, bupivacaine skull block, IV fentanyl. All of them yielded varying results and thus it was identified that further research would be required to identify the ideal modality. Dexmedetomidine, a selective alpha 2 adrenoreceptor agonist has sedative, analgesic, and anaesthetic sparing effect. So we compared dexmedetomidine with the commonly used method of local lignocaine infiltration at pin sites for attenuating the hemodynamic response. Thus it was found that dexmedetomidine is more effective in controlling the hemodynamic response than local lignocaine infiltration. Despite dexmedetomidine having side effects such as hypotension and bradycardia which can be detrimental in neurosurgical patients we did not observe any such side effects when dexmedetomidine was slowly infused over 10 minutes in a dose of $1 \mathrm{mcg} / \mathrm{kg}$.

\section{CONCLUSION}

It was concluded that $1 \mathrm{mcg} / \mathrm{kg}$ of dexmedetomidine infused slowly over 10 minutes is superior when compared to local infiltration of $2 \%$ lignocaine in attenuating the hemodynamic response to skull pin holder during craniotomy.

\section{REFERENCES}

1. Levin R, Hesselvik JF, Kourtopoulos H, et al.. Local anesthesia prevents hypertension following application of the May field skullpin head holder. Acta Anaesthesiol Scand. 1989; 33:277-279.

2. Jamali S, Ancher D, Ravussin P, et al.. The effect of skull-pin insertion on cerebrospinal fluid pressure: and cerebral perfusion pressure influence of sufentanil and fentanyl. Anesth Analg. 1997; 84:1992-1296.

3. Engberg M. Melsen0 NC, Herlevsen P, et al. Changes of blood pressure and cerebral arteriovenous oxygen content of blood pressure and Article cerebral arteriovenous oxygen content difference (ADOP) with and without bupivacaine scalp infiltration during craniotomy. Acta Anaesthesiol Scand. 1990; 34:346-349.

4. Doblar DD, Lim YC, Baykan N, et al.. A companion of alfentanil, esmolol, lidocaine, and thiopental sodium on the hemodynamic response to insertion of headrest skull pins. J Clin Anesth. 1996; 8:31-35.

5. Ozkose Z, Yardim S, Yurtlu S, et al.. The effect of intravenous fentanyl and lidocaine infiltration on the hemodynamic response to skull pin placement. NeurosurgRev. 2001; 24:35-37

6. Yildiz K, Madenoglu H, Dogru K, et al.. The effect of intravenous fentanyl and lidocaine infiltration on the hemodynamic response to Aull pin insertion Neurosurg Rev.2005; 17:9-12

7. Dayer Berger MM, Ruvussin P, Frankhan H, et al.. Effect of three pretreatment techniques on hemodynamic and CSFP response to skull pin head-holder application during thiopentone isoflurane or propofol anaesthesia. J Neurosurg Anesth 1989; 1:227-232.

8. Desborough JP, The stress response to trauma and surgery $\mathrm{Br}$. Anaesth. 2008; 85:109-117.

9. Kennedy BC, Hall GM Neuroendocrine and inflammatory aspects of surgery: do they affect outcome. Acta Anaesthesiol Belg. 1999; 50:205-209.

10. Savola JM, Vertanen R. Central alpha-2 adrenoceptors are highly stereoselective for dexmedetomidine the dextro enantiomer of medetomidine, Eur 1 Pharmacol 1991; 195:193-199.

11. Talk $\mathrm{P}$, Chen $\mathrm{R}$, Thomas $\mathrm{B}$, et al. the hemodynamic and adrenergic effects of perioperative dexmedetomidine infusion after vascular surgery. Anesth Analg. 2009; 90:834-839. 
12. Tankskanen PE, Kytta JV, Randell TT, et al.. Dexmedetomidine as an anaesthetic adjuvant in patients undergoing intracranial tumour surgery: a double-blind, randomized and placebocontrolled study. Br J Anaesth. 2006; 97:658-665.

13. Maze M, Virtanen R, Daunt D, et al. . Effects of desmodetodinc, novel imidazole sedative- anaesthetic agent, on adrenal steroidogenesis: in vivo and in vitro studies. Anesth Analg 1991; 73:204-208

14. Aho M, Scheinin M, Lehtinen AM, et al. intramuscularly administered dexmedetomidine attenuates hemodynamic and stress hormone responses to gynecologie laparoscopy: Anesth Analg. 1992; 75:932-939.
15. Gonzalez RM, Mason RJ. Peterson R, Hemodynamic response to application of neurosurgical skull-pin head-holder. Anesthesiol Rev. 1987; 14:53-54.

16. Low JM, Harvey JT. Prys-Roberts C, et al. . Studies of anaesthesia relation to hypertension VII: Adrenergic responses to laryngoscopy. Br J anaesth. 1986; 58:471-477.

17. Jellish WS, Theard MA, Cheng MA, et al.. The effects of clonidine premedication and scalp infiltration of lidocaine on hemodynamic response to laryngoscopy and skull pin head-holder insertion during skull base procedures. Skull Base. 1901; 11:169-176.

18. Costello TG, Cormack JR. Clonidine medication decrease hemodynamic responses to pin head-holder application during craniotomy. Anesth Analg. 1998; 86:1001-1004.

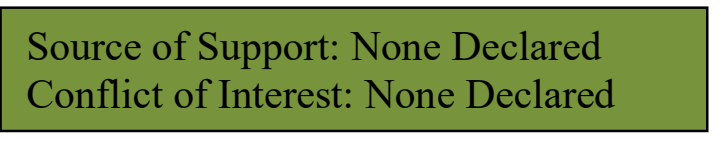

Policy for Articles with Open Access:

Authors who publish with MedPulse International Journal of Anesthesiology (Print ISSN:2579-0900) (Online ISSN: 2636-4654) agree to the following terms: Authors retain copyright and grant the journal right of first publication with the work simultaneously licensed under a Creative Commons Attribution License that allows others to share the work with an acknowledgement of the work's authorship and initial publication in this journal.

Authors are permitted and encouraged to post links to their work online (e.g., in institutional repositories or on their website) prior to and during the submission process, as it can lead to productive exchanges, as well as earlier and greater citation of published work. 